\title{
Consumer Perception of Government Regulations in the Marketing of Consumer Products in Nigeria
}

\author{
A. E. Ndu Oko (Corresponding author) \\ Department of Marketing, Abia State University, Uturu-Nigeria \\ Tel: $+2348057851630,+2348064868940$ \\ E-mail: a.e_nduoko@yahoo.com \\ C. Elisha Anyanwu \\ Department of Marketing, Abia State University, Uturu-Nigeria
}

Doi:10.5296/ ijld.v5i2.7842 URL: http://dx.doi.org/10.5296/ ijld.v5i2.7842

\begin{abstract}
The Nigeria society is littered with consumer product regulatory policies and agencies, however the degree of relevance and efficiency of these agencies is a-judged low compared to expectations. This situation is traced to the poor level of cooperation that exists between these agencies and target beneficiaries of the policies. This work thus studied consumer product marketing environment with selected regulatory agencies, producers of consumer products and consumers as targets and sources of data of the purpose of ascertaining the perception of consumers of government regulations. Data were analyzed based on Likert ranking scale built on the use of the nominal, ordinal and interval scales as well as the Spearman's rank correlation co-efficiency and analysis of variance (ANOVA) statistics. Identified as problems are paucity in the presentation of the stimuli of regulatory messages, poor choice of media, inability to optimize the attributes (characteristics) of target markets in message building, poor management of regulatory agencies personnel among others. Given these, the paper recommends efficiency in media choice and management, consumer market research for the optimization of the attributes of the target market in message planning and development, the creation of balance in message building based on the urban-rural imbalance of target market structure, efficiency in regulatory agencies' personnel management and socialization effort in agencies' personnel among others.
\end{abstract}

Keywords: Consumer, consumer products, Nigeria, perception, regulation and stimuli. 


\section{Introduction}

Perception influences behaviour as it determines the rate and level of acceptability of public and private sector market offers; hence it is associated with critical activities that link the consumers to vendors as individuals or groups and the situations and marketing influences -Hawkins, Best \& Coney (2001). Regulations and regulatory policies as public sector market offers especially in the consumer products as goods and services marketing are poorly accepted in Nigeria based on the perceptions the various publics hold concerning consumer product marketing regulatory policies; hence the cooperation government receives in the implementation of these policies as consumer attitude -Anyanwu (2005), is considered low. Given this, consumers' attitude toward government and its regulatory policies and their abilities at protecting the consumers is rated low-Udeagha (2003). This accounts for the cool response of the general and special publics to calls by government for assistance in the implementation of the projects of the regulatory policies. This suggests and supports the linearity that exist between target markets' perception and attitude, as attitudes spring from thoughts or cognitive process, motivational feelings and action tendencies -Umeh (2008)

\section{Conceptual Frame Work:}

Poverty in Nigeria is traced to political issues, thus defensively governments have always encouraged consumerism or have directly been involved in the management of hunger, environmental degradation and other problems that have commonalities with poverty-www.globalissues.org.

These supposed protections of the citizens have always involved the use of regulatory agencies as individual bodies or in collaboration -Akin \& Shue (2013), who go about developing and executing regulatory policies without due consultations with Nigeria consumers for the purpose of optimizing the regulatory objectives, rather consumers as a class that is affected by government decisions and policies have no impact in regulatory policies formulation -Aimiuwa in Akin \& Shue (2013).

Given this, the perception of consumers of government regulatory especially in the marketing of consumer products has often yielded less than expected in policies and activities.

The questions that call for the attention of this work are:

- To what extent have these agencies achieved the objectives of consumer protection?

- What level of cooperation exists between these bodies and the specific and general publics of Nigeria?

- Do these agencies optimize the attributes of the Nigeria publics in terms of urban-rural area dwelling, literacy level, poor concern for public notice, poverty, attitude of always being in a hurry, hasty conclusions, generalization of opinion as well as being influenced by opinion leaders, high level of environmental influence rate, immediate purchase decision among others in the presentation of their regulatory policy promotions. 


\section{Macrothink}

Following these, what is the perception of consumers given governmental regulatory policies in consumer product industry in Nigeria?

\section{Theoretical Frame Work:}

literature abound in the area of regulation and control of the activities of marketers of consumer products in Nigeria as well as those of consumerism as contributions date back to the early 1970's. Some of these literature include- Adinoyi, Ogunseitanm, Okwara, Ogbeide \& Anukwe (1988); Agbonifoh (1987); Akorete (1980), Ekenma (1987), Igboka (1988); Odutayo (1989), Ogbuma (1985), Oloke (1987), Olusoga (1978) Agbonifoh, Ogwo Nnolim and Nkamnebe (2007), Ayozie (2013), Oko \& Ogwo (2014), Oko \& Agbonifoh (2014), Oko \& Osuagwu (2013), Adeknmbi (2013), Ogbide (1981), Oghuma, Arinze \& Mba (1988), Ogwo (1999), Omenazu (2010) among others. These literatures have always highlighted government regulatory policies, and the prospects and challenges in the activities of consumer protection. Record(s) however do not exist on efforts at determining the perception of consumers to these regulatory policies as index for evaluating consumer level of acceptance of these regulatory bodies and as a measure of cooperation between regulatory agencies and the publics for the realization of the objectives of these policies and regulatory activities.

Given these, this work assessed for the positivity or otherwise, the perception of consumers to government regulatory policies in the marketing of consumer products as basis for evaluating of the effectiveness or otherwise of these policies and agencies.

\section{Significance of the Study:}

While existing literature lay emphasis on the challenges especially in the area of corruption among government officials, the high level of illiteracy among consumers and unwilling members of the publics to report cases of market exploitation, the determination of the perception of target markets to government regulatory policies and activities in the marketing of consumer products will aid the government position and re-position its regulatory policies and activities in content, context and structure to address the factors that create negative rather than positive perception and influence the attitude of the target market for desired cooperation with government and for desired synergy in relationships and for policies and activities objectives actualization.

\section{Objective of the Study:}

The principal objective of this exercise is to determine factors that create negative consumer perception for government regulatory policies and to address the identified variables as means to stimulating cooperation between government agencies as initiators and implementors of regulatory policies and activities and the target markets for ease in actualization of the objectives of the regulatory policies and activities. 


\section{Research Questions:}

Consumer perception is influenced by exposure, attention and interpretation. These stimuli generate impacts over a period of time-Hawkins, Best \& Coney (2011), thus influence attitude for like or dislike and or cooperation or non-cooperation of stimuli and target market. Thus these research questions are considered important.

- What is the relationship between the characteristics of the stimuli on which regulatory policies, activities and messages are built and the ability of the consumers to perceive the stimuli?

- At what rate do the target markets as publics organize and integrate the different regulatory policies and activities stimuli presentations for desired perception?

- What inferences do the target publics of regulation policies have concerning the image of government, its agencies, and the regulatory policies, methods of policies implementation and desired effects of the policies as bases for assessing and accepting the policies and agencies?

\section{Research Hypotheses:}

The study has the following as thrust hypotheses; as stated in their null forms

H0 $0_{1}$ There is no significant linear relationship between the characteristics of the stimuli on which regulatory policies and messages are presented and the ability of the target markets to perceive the stimuli.

$\mathbf{H 0}_{2}$ : Regulatory agencies' presentations as stimuli for the presentation of the regulatory policies do not significantly enhance the organization and integration of message(s) for the desired perception.

H03: The inferences the target markets have concerning the regulatory policies, the products and their presentations (activities) do not significantly influence consumer total perception of the regulatory bodies' and policies

\section{Organization of the Study:}

This study is organized in 15(fifteen) sections of introduction with highlights of the theoretical and conceptual frame work; significance of the study; objectives of the study, research questions and hypotheses; literature review; methodology; analyses; findings and discussions, conclusion, recommendations and references.

\section{Literature:}

Government as a public sector marketer is challenged with (by) the responsibility of protecting the consumers given the quality and quantity of offer made available by both public and private sector enterprises and to ensure that consumers receive fair value in their exchange relationships -Agbonifoh, Ogwo, Nnolim \& Nkamnebe (2007), Oko \& Osuagwu (2013), Oko \& Ogwo (2014) Nwokoye (2003) and Ijewere \& Obeki (2011), hence has in the past as currently introduced legislations and agencies as well as policies that monitor and 
superintend public and private sector productive activities in goods and services. These agencies include the service compact (SERVICOM) Consumer Protection Council (CPC), Federal Environmental Protection Agency (FEPA), National Agency for Foods and Drugs Administration and Control (NAFDAC), Nigeria Drug Law Enforcement Agency (NDLEA), Standards Organization of Nigeria (SON), Nigeria Communication Commission (NCC), Nigeria Deposit Insurance Company (NDIC), Assets Management Corporation of Nigeria (AMCON), Economic and Finance Crimes Commission (EFCC), Independent Crime Protection Commission (ICPC), The Central Bank of Nigeria (CBN) and others-Halliru (2012), Ayozie (2012) and Oko \& Osuagwu (2013). These agencies and their services are poorly accepted by the target markets that they are expected to protect their interests, hence the desired level of cooperation between these agencies and the public is not achieved, thus effectiveness of these agencies is reasonably retarded. Poor interpretations of the regulatory policies and activities based on the inability of the agencies to optimize the attributes of the target markets for congruence with the characteristics of the message is also worthy of note; consequently this discussion is considered important.

\subsection{Marketing Stimuli and Consumer Perceptions:}

Government requires stimuli as physical, visual or verbal communication inputs to influence the rate and level of target markets acceptance of its market offers as regulatory policies and activities in the present competitive and global market. These stimuli are marketing and environmental in characteristics. Marketing stimuli as controllable variables are designed to influence the target markets (in their packaging, contexts and physical properties) of the government consumer product regulatory policies and activities, thus must be communication designed to influence product consumers' (regulatory policies) behaviour, and must have constant exposure capacity to the markets, for acceptance and policies' objectives actualization-Assael (1992).

To achieve the desired objectives of the creation of favourable consumer perception for government consumer product regulatory policies, the communication of these policies and activities must aim at developing acceptable product concept-Ogwo (2012), as the benefits of these regulatory policies are directed to the needs of the target markets based on messages, symbolisms and images. The development of consumer product regulatory concepts leads to the development of activities' built around the marketing plan. Factors that determine which market (-consumer product) where the regulatory stimuli are to be perceived and their interpretations are influenced by the characteristics of the stimulus and ability of the target market to perceive the stimulis -Assael (1992), as both interact to influence consumer perceptions.

\subsubsection{Stimulus Characteristics Affecting Perception:}

The use of promotion and its elements in the presentation of consumer regulatory policies and activities by government to the target publics has the ability of making the message more likely to be perceived as desired, given the features of marketing communication -(advertising,) as these features effect the sensory and structural elements of the target markets. While the sensory elements relate to the smell, feeling, sound and taste of the 
presentations, the structural factors relate to the size, position, colour, contrast and novelty of the presentations.

\subsubsection{Consumer Characteristics Affecting Perception:}

Consumer characteristics considered determinants in stimuli perceptions include: ability to discriminate between stimuli, propensity to generalize from one stimulus to another and perceptual style.

The message to be presented or presented should aid the target markets discriminate between stimuli of the presentations of different government consumer products regulatory policies and activities and agencies as situation of no -difference negates and retards perception ability. Government (public) sector advertisements may be adopted to convey regulatory policies as discrimination is created between programmes and activities of the different regulatory agencies.

Consumers as target markets should be able to detect variations in light, sound or other stimuli of the message presentations as means of determining their threshold level, for sensitivity measurement. This is important in comparing two stimuli for differential thresholds -just-noticeable difference.

To ensure significant differential threshold in the presentation of the different regulatory policies and activities of the different agencies in the area of consumer protection, reasonably changes in marketing stimuli, in intensity, length, content, context and structure are advocated for, in the blending of the intra elements of promotion for congruence with the characteristics and traits as features of the natural and artificial personalities as focus on in the presentation of the policies and programmes, bearing in mind the provisions of Weber's Law -Assael (1992) and the limitations to the applicability of this law, as it contradicts the basic principle in economics 'that increasing price will result in greater price sensibility and a decrease in quantity consumed'.

The presentation of the product regulatory programmes must appreciate the existence of an absolute threshold below which the consumer cannot for any reason detect stimulus for programme perception, and adaptation level as point at which the consumer no longer notices a frequently repeated stimulus as part of programme presentation.

It is important also to consider the process of stimulus generalization as relevant when two or more stimuli are seen as similar (contiguous), as the effects of one can be substituted for the effects of the others and considered equally important are the consumer characteristics, that affect perception as well as the perceptional style. This considers the consumers' propensity to processing information in different but definite manners as is influenced by the willingness of the target markets to consider new information, and the possibility of information contradicting their beliefs.

\subsection{Perceptional Selection, Organization and Interpretation:}

The process of and processing of perception is made up of selection, organization and interpretation, and are considered thus: 


\subsubsection{Selection:}

Consumers of product and their quantity and quality regulatory policies, activities and agency components are classified and evaluated based on how they respond to stimuli as they impact on their needs and attitudes. The selection of stimuli is based on the consumers' psychological set of variables as are of impact on consumers' attention. Promotion mix elements influence attention, while selective perception as response to marketing stimuli is influenced by the combination of needs, attitude, experiences and personal characteristics. Based on this, it may be reasonable to ask, how do Nigerians perceive the activities of the various regulatory agencies especially as different members of the target markets perceive these agencies and their policies bed rocks differently, in terms of promotion, implementation and explicit and implicit motives, as selective perception depending on the nature, content and context, structure of the policy and implementation strategy aid the evaluation of programmes (policies and regulatory activities) that meet the needs of the defined target markets and to confirm adequately or otherwise to their beliefs and pre-disposition as means of avoiding cognitive activities and informational clusters. The process of selective perception as exposure, attention, comprehension and retention ensures that the target market receive information most relevant to their needs and for regulatory agencies' activities evaluation just as brands, hence could lead to perceptual vigilance or perceptual defence.

Nigerians have always made efforts at obtaining information about these regulatory agencies their activities and policies that are consistent with their beliefs about these institutions and activities based on selective perception, or interpretation of information to confirm to these beliefs for perceptual equilibrium, especially within defined set of psychological values. But most common features are perceptual disequilibrium based on rejection of contradictory information (contrast) or based on closely related views-assimilation.

\subsubsection{Perception Organization:}

Target markets as focus of marketing communication of the regulatory policies and activities are exposed to various and varieties of information from particular as well as various sources. These pieces of information are organized and integrated into meaningful whole for better comprehension and response.

For effectiveness in perception organization and for integration, the information source as government (and the various regulatory agencies) is expected to provide complete information to the consumer publics as incomplete information creates the tendency for the audience to fill in the missing stimuli elements based on self conceived source. The target audience is expected to be encouraged in their information chunking (grouping), for ease in evaluation of varieties of activities embedded in the product regulation policies and activities in the areas of implementation; components of activities; anticipated end results, societal impacts among others as attributes.

Regulatory related pieces of information need to be presented based on credible media as platforms. This is because target markets perceive objects as information and activities based on the context of the presentation. The platform of information presentation influences the 
perception of the presentations. Messages in context should be influenced by the principle of figure and group, for ease in distinguishing prominent figures from the less prominent ones as background.

Following this discourse, it may be right to assess the information presentation activities of the product regulatory agencies in Nigeria in terms of closure, grouping and context.

\subsubsection{Perception Interpretation:}

Target audience of the product (in quality and quantity) of regulatory agencies, select and organize stimuli for message interpretation based on the principles of categorization and influence. While categorization aids the target markets in the act of processing known information, for speedy and efficient interpretation, and classification of new information; inference is associated with the development of association between stimuli. This work assessed the rate at which regulatory message audience in Nigeria interpret the message of these agencies.

\section{Methodology:}

It is based on the study of selected firms involved in the marketing of tangible and intangible consumer products, selected regulatory agencies and selected consumers of these firms' products across six geo-political zones in Nigeria.

Three (3) sets of structured questionnaires were in addition to structured interview schedule used to elicit data (information) from basic audience of the study-producers, regulatory agencies and consumers. Data were scaled based on the nominal, ordinal and interval scaling principles and were ranked based on the Likert ranking principle. The hypotheses were tested using the spearman's rank correlation co-efficiency and analysis of variance (ANOVA) statistics

\section{Analysis:}

The bases of the analysis, interpretation for conclusion and recommendations as output of this research work are the data presentation thus:

\section{Table 1:1 Questionnaire Distribution and Return:}

Table 1:1 Questionnaire Distribution and Return:

\begin{tabular}{lccccc}
\hline $\begin{array}{l}\text { Target } \\
\text { Respondents }\end{array}$ & $\begin{array}{c}\text { Number } \\
\text { Issued }\end{array}$ & $\begin{array}{c}\text { Number } \\
\text { Returned }\end{array}$ & $\begin{array}{c}\text { Percentage } \\
\text { Returned }\end{array}$ & $\begin{array}{c}\text { Number } \\
\text { Valid }\end{array}$ & $\begin{array}{c}\text { Percentage } \\
\text { Valid \& Returned }\end{array}$ \\
\hline - Regulatory agencies & 30 & 21 & $70 \%$ & 16 & 76 \\
- Firms in consumer & & & & & \\
$\quad$ goods production & 30 & 22 & $73 \%$ & 18 & 81 \\
- Consumers & 138 & 110 & $85 \%$ & 80 & 73
\end{tabular}

Table 1.1 shows an average questionnaires return rate of $76 \%$ and validity rate on returned questionnaires of $77 \%$. The opinion of the research is that these percentage rates of return and validity of questionnaires respectively are high enough to form basis for making valid conclusions and recommendations as products of this research exercise. 


\section{Test of Hypotheses:}

\section{Hypothesis 1:}

$\mathbf{H O}_{1}$ : There is no significant linear relationship between the characteristics of the stimuli on which regulatory policies and activities are presented and the ability of the target markets to perceive the stimuli.

Table 1.2 Consumer perception of stimuli of presentation of government regulatory policies and activities and the impact on the presentations on product consumers

Issue of

Assessment
Regulatory

Agencies
Pharmaceutical

Consumers Firms

- Efficiency in the implementation of ceasure of poor products policies

15

- Impact of product registration and certification on product acceptance

- Impact of wrong assumption of government policies 12

- Impact of insufficient facts on regulation

- Agency education and promotion, based on rural /urban imbalance

Total

Multiplier

Actual weight assessment

Standard weight assessment

Actual weight as percentage of standard
14

10

$\underline{16}$

67

$\underline{15}$

1005

2000

50.2
18

14

16

12

$\underline{15}$

75

$\underline{15}$

1125

2250

50.0
32

35

27

40

$\underline{34}$

178

15

2670

10,000

26.7

Based on computation on table 1.2, the regulatory agents, manufacturing and producing firms and consumers of consumer products assessed the impact of stimuli of presentations of government regulatory policies and activities on the presentation of consumer products based on the perception of the stimuli at $50.2 \%, 50.00 \%$ and $26.7 \%$ respectively. These assessments are 50 percent and above, thus standard and above for the regulatory agencies and manufacturers and producers of consumer products and low for the consumers of these products. Therefore, this work cannot conclude with certainty that consumer perceptions of government regulatory policies and activities have nor do not have significant linear relationship with the characteristics of the stimuli on which regulatory policies and activities are presented and the ability of target market to perceive the stimuli. Thus, neither the null nor the alternative hypothesis is rejected nor accepted. Based on this, the work thus tests for significance in difference between these assessments.

To test for the significance of difference or otherwise between the mean ratings of the 


\section{Macrothink}

International Journal of Learning \& Development

ISSN 2164-4063 2015, Vol. 5, No. 2

personnel of the regulatory agencies, the personnel of the firms involved in the production of consumer products and consumers of consumer products, the hypothesis is re-structured thus:

$\mathbf{H}_{\mathbf{0}}: \quad\left(\mu_{1}=\mu_{2}=\mu_{3}\right)$ there is no significant different between the rating of consumer perception of government regulatory policies and activities on the consumption of consumer products in Nigeria by the 3 sets of respondents.

$\mathbf{H}_{1}: \quad\left(\mu_{1} \neq \mu_{2} \neq \mu_{3}\right)$ there is significant difference between the rating of consumer perception of government regulatory policies and activities on the consumption of consumer products in Nigeria by the 3 sets of respondents.

Where $\mu_{1} \quad \mu_{2}$ and $\mu_{3}$ are means of the rating of the three groups of respondents

$$
\begin{array}{rll}
\text { Based on } \mathrm{f}=\underline{\mathrm{V}_{\mathrm{b}}}=\underline{\text { between groups variance }}= & \underline{\mathrm{S}^{2}} \underline{\mathrm{B}} \\
\mathrm{V}_{\mathrm{w}} & =\text { within groups variance } & \mathrm{S}^{2}{ }_{\mathrm{W}}
\end{array}
$$

Where: $\mathrm{V}_{\mathrm{B}}=\underline{\mathrm{SSB}}$, and

$$
\begin{array}{ll}
\mathrm{df}_{\mathrm{B}} & \\
& \frac{\mathrm{SSW}}{\mathrm{Dfw}}
\end{array}
$$

\section{Table 1.3 Computation of F-ratio}

Rating of Consumer perception of the stimuli of presentation of Government Regulatory Policies and activities on the Consumption of consumer Products in Nigeria by the three (3) sets of respondents based on acceptance of stimuli:

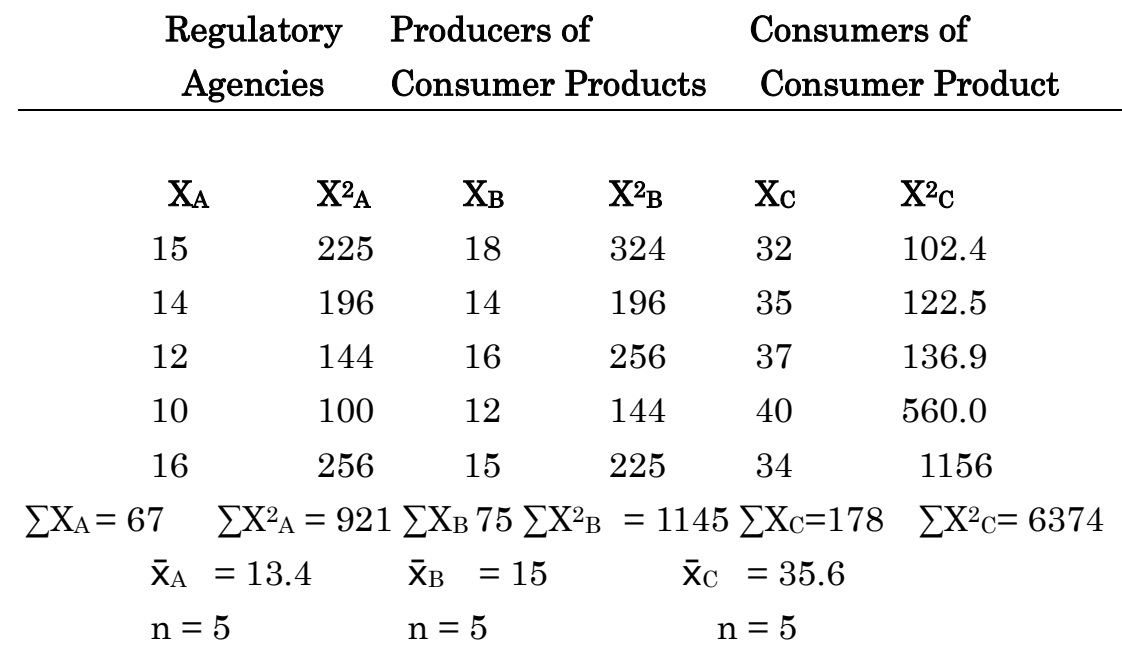


$\mathrm{SSB}=1490.5 ; \quad \mathrm{SSW}=804$ and SST $=1570.90$

$$
\mathrm{V}_{\mathrm{B}}=\frac{\underline{\mathrm{SSB}} \text { and }}{\mathrm{dfB}} \mathrm{V}_{\mathrm{W}}=\underline{\mathrm{SSW}}
$$

Where: $\quad \mathrm{df}_{\mathrm{B}}=$ number of groups $(\infty)$ minus 1

$$
\begin{aligned}
& \mathrm{df}_{\mathrm{w}}=\text { number of the classes within each sub group }(\mathrm{s}) \text { minus } 1 \\
& \mathrm{~V}_{\mathrm{B}}=\text { between groups } \\
& \mathrm{V}_{\mathrm{W}}=\text { variance within groups }
\end{aligned}
$$

Substituting for mathematical notation:

$$
\begin{aligned}
\mathrm{V}_{\mathrm{B}}=\underline{\mathrm{SSB}} & =\frac{1490.5}{2}=745.25 \\
\mathrm{dfb} & =\frac{80.4}{12} \\
\mathrm{~V}_{\mathrm{W}}= & =6.7
\end{aligned}
$$

\begin{tabular}{|c|c|c|c|c|c|c|c|c|c|}
\hline $\begin{array}{l}\text { Source } \\
\text { variance }\end{array}$ & $\mathrm{df}$ & $\begin{array}{l}\text { Sum of } \\
\text { square ss }\end{array}$ & $\begin{array}{l}\text { Mean o } \\
\text { squares }\end{array}$ & & $f^{-}$cal & $\begin{array}{l}\text { Critical } \\
\text { value of }\end{array}$ & f & Significance & Decision \\
\hline Between grou & p 2 & $\mathrm{SSB}=1490.5$ & $\mathrm{~V}_{\mathrm{B}}=$ & \multicolumn{2}{|c|}{745.25} & & & \multirow{3}{*}{ Significant } & \multirow{3}{*}{ Accept $\mathrm{H}_{1}$} \\
\hline Within group & 16 & $\mathrm{SSW}=80.4$ & $\mathrm{~V}_{\mathrm{W}}=$ & 6.7 & 111.23 & 1.73 & & & \\
\hline Total & 18 & 1370.9 & \multicolumn{3}{|c|}{751.95} & & & & \\
\hline
\end{tabular}

Substituting for the $f$. ratio mathematical notation:

$$
\begin{array}{ccc}
\mathrm{f}= & \underline{\mathrm{V}}_{\underline{\mathrm{B}}_{-}}= & \frac{745.25}{6.7} \\
\mathrm{~V}_{\mathrm{W}} &
\end{array}
$$$$
=111.23
$$

Table 1.4 Summary of ANOVA: 
At 0.05 level of significance, the critical value of $\mathrm{F}$ is given as 1.73 ; $\mathrm{f}>\mathrm{f} 005$ (1.73), thus $\mathrm{H}_{1}$ is accepted. The conclusion is that significant difference does not exists between the assessments of consumer perception of government regulatory policies and activities on the consumption of consumer products in Nigeria and the ability to perceive stimuli of presentation.

\section{HYPOTHESES II}

Hypothesis II measures the impact of inefficiency in the management of the activities of personnel of the regulatory agencies on the perception of consumers as stimuli for the perception of regulatory policies and activities. This is stated as thus:

$\mathbf{H O}_{2}$ : Regulatory agencies presentations, policies and activities as stimuli tailored around agencies' personnel do not significantly enhance the organization and integration of messages for the desired perception.

The analysis is based on the response from the consumers of consumer products and personnel of firms involved in the production and marketing of consumer products in Nigeria. This is shown in table 1.5.

Table 1.5 Assessment of poor management of the activities of personnel of regulatory agencies on the perception of consumers of consumer products of regulatory policies and activities in Nigeria.

\begin{tabular}{lcc}
\hline Issues of Assessment & $\begin{array}{c}\text { Personnel of } \\
\text { Firms }\end{array}$ & Consumers \\
\hline - $\quad$ Personnel socialization & 16 & 74 \\
- Ostentious lifestyle & 15 & 76 \\
- Discipline among personnel & 14 & 78 \\
- Impact of poor judiciary procedures & 13 & 80 \\
- Mismanagement and exaggeration of & & \\
$\quad$ promotion and its activities & $\underline{12}$ & $\underline{75}$ \\
$\quad$ Total & 77 & 383 \\
$\quad$ Multiplier & $\underline{15}$ & $\underline{15}$ \\
Actual weighted assessment & 980 & 5745 \\
Standard weighted assessment & 2000 & 10,000 \\
Actual weighted assessment as a & & \\
percentage of standard assessment & 49.00 & 57.45
\end{tabular}

Following the calculation in table 1.5. Inefficiency in the management of activities personnel of the regulatory agencies is high for consumers and low for personnel of firms in the production of consumer products. This is at $49.00 \%$ and $57.45 \%$ respectively for personnel of firms in the production and marketing of consumer products and consumers of the products. Thus the hypothesis, "regulatory agencies presentations of policies and activities as stimuli 


\section{Macrothink}

International Journal of Learning \& Development

ISSN 2164-4063

2015, Vol. 5, No. 2

do not significantly enhance the organization and integration of messages for the desired perception" is neither accepted nor rejected as the projected statement "inefficiency in the management of the activities of personnel of the regulatory agencies does not have significant impact on the perception of consumers' is neither accepted nor rejected. This hypothesis is thus subjected to further analysis.

To test for the correlation between the assessments of personnel of the firms in the consumer products industry and product consumers, the spearman's rank correlation coefficient represented as mathematical notation (2) is adopted:

$$
\mathrm{r}_{\mathrm{s}}=1-\frac{6 \sum \mathrm{d}^{2}}{\mathrm{n}\left(\mathrm{N}^{2}-1\right)}
$$

Here: $\begin{aligned} \mathrm{d} & =\text { the difference between each rank of corresponding values of } \mathrm{x} \text { and } \mathrm{y} \\ \mathrm{n} & =\text { the number of pairs of values. }\end{aligned}$

The hypotheses are adjusted thus:

$\mathbf{H}_{\mathbf{0}}$ : There is no significant difference between the assessments of personnel of firms in the production and marketing of consumer products and those of product consumers on the impact of in-efficiency in the management of the activities of personnel of regulatory agencies as stimuli on the perception of consumers

$\mathbf{H}_{1}$ : There is a significant difference between the assessments of personnel of firms in the production and marketing of consumer products and those of product consumers on the impact of inefficiency in the management of the activities of personnel of regulatory agencies as stimuli on the perception of consumers.

Values as basis of calculation are shown on Table 1.6 
Table 1.6: The various components of the $\mathbf{r}^{\mathrm{s}}$

\begin{tabular}{|c|c|c|c|c|c|}
\hline $\begin{array}{l}\text { Personnel of } \\
\text { Firms (x) }\end{array}$ & $\begin{array}{c}\text { Consumers } \\
\text { (y) }\end{array}$ & $\begin{array}{l}R_{x} \\
\text { ranking of } \\
\quad X\end{array}$ & $\begin{array}{l}R_{y} \\
\text { ranking of } \\
y\end{array}$ & $\begin{array}{c}\mathbf{R}_{\mathrm{x}} \mathbf{R}_{\mathrm{y}} \\
=\mathrm{d}\end{array}$ & 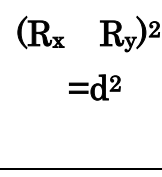 \\
\hline 16 & 74 & 5 & 1 & 4 & 16 \\
\hline 15 & 76 & 4 & 3 & 1 & 1 \\
\hline 14 & 78 & 3 & 4 & -1 & 1 \\
\hline 13 & 80 & 2 & 5 & -3 & 9 \\
\hline 12 & 75 & 1 & 2 & -1 & 1 \\
\hline
\end{tabular}

Substituting for the formula:

$$
\begin{aligned}
& r_{\mathrm{s}}=1-\quad \underline{6 \sum \mathrm{d}^{2}} \\
& \mathrm{~N}\left(\mathrm{~N}^{2}-1\right) \\
& =1 \underline{6 \sum 28^{2}} \\
& 5(25-1) \\
& =\quad 0.4
\end{aligned}
$$

The test of significance $\mathrm{Q}_{\mathrm{rs}}$, for this test statistic is conducted using

$$
\begin{aligned}
\mathrm{Q}_{\mathrm{rs},} \quad=\frac{\mathrm{Z}-1}{\sqrt{\mathrm{n}}-1} \\
=\frac{1.96(1)}{\sqrt{ } 5-1} \\
=1.59
\end{aligned}
$$

Where $\mathrm{Z}$ is standard normal deviation and which at 0.05 level of significance is given as 1.96 


\section{Macrothink}

International Journal of Learning \& Development

ISSN 2164-4063

2015, Vol. 5, No. 2

Based on the results of the computations, the decision is to accept the null hypothesis since $r$ is less than $\mathrm{Q}_{\mathrm{rs}}$. It is therefore concluded that the test is insignificant at 0.05 level of confidence; hence the alternative hypothesis is rejected. The conclusion is that there is a significant difference between the assessments of personnel of the firms' in the production and marketing of consumer products in Nigeria and those of consumers on the impact of inefficiency in the management of the activities of the personnel of product regulatory agencies on the perception of consumers. Given this, it is concluded that the regulatory agencies presentations of policies and activities tailored around activities of personnel of the agencies as stimuli do not significantly enhance the organization and integration of message(s) for the desired perception of regulatory policies and activities in Nigeria.

\section{TEST OF HYPOTHESIS III}

\section{Hypothesis iii is stated thus:}

H03: The inferences the target markets have concerning the regulatory policies, the products and their presentations (activities) do not significantly influence consumer total perception of the regulatory agencies' policies.

Data basis of this evaluation is presented in table 1.7

Table 4.7: Rating of the inferences of the target markets on regulatory policies, activities and their presentations as indicies of perception.

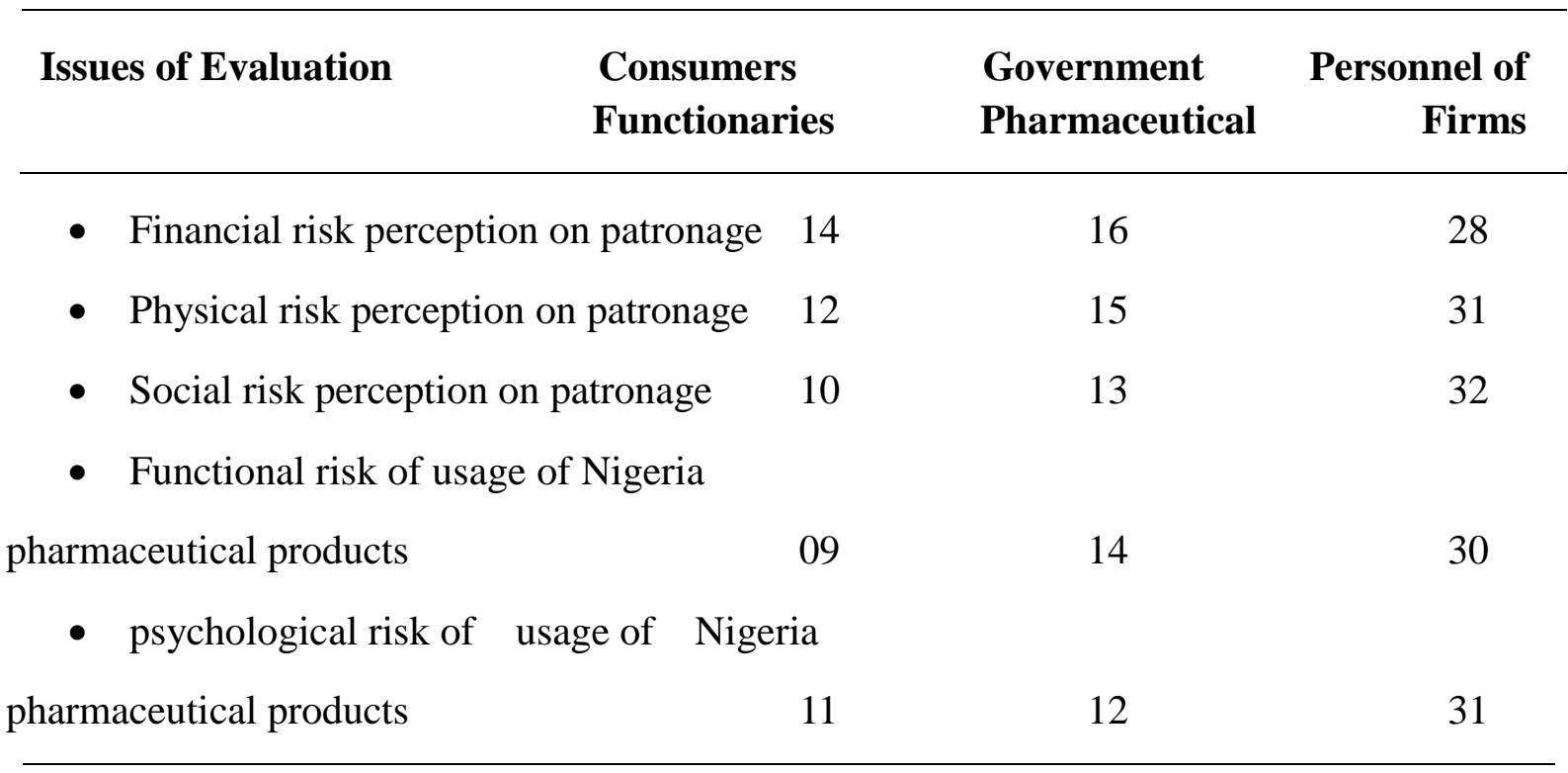

The hypothesis as formulated is restated thus:

$\mathbf{H}_{0}: \quad\left(\mu_{1}=\mu_{2}=\mu_{3}\right)$ there is no significance difference between the inferences of 


\section{Macrothink}

International Journal of Learning \& Development

ISSN 2164-4063 2015, Vol. 5, No. 2

consumers, government functionaries (regulatory agencies) and personnel of firms in the production and marketing of consumer products of regulatory policies, activities and their presentations as indicies of consumer total perception of the policies.

$\mathbf{H}_{1}: \quad\left(\mu_{1} \neq \mu_{2} \neq \mu_{3}\right)$ there is significant difference between the inferences of consumers, government functionaries (regulatory agencies) and personnel of firms in the consumer products of regulatory policies, activities and their presentation as indicies of consumer total perception of the policies.

Where $\mu_{1}, \mu_{2}$ and $\mu_{3}$ are means of the rating of the 3 (three) groups of respondents

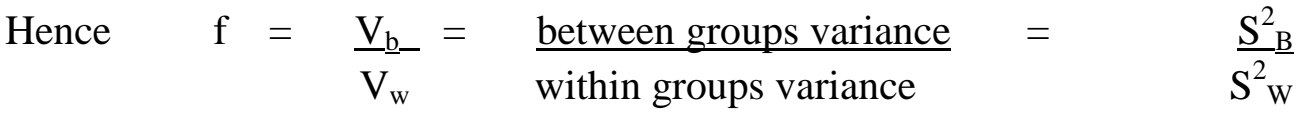

Where $\quad V_{B}=\underline{S S B}$, and $V_{w}=\underline{S S W}$

$\mathrm{dfb} \quad \mathrm{dfw}$

The computation of the data is shown in table 1.8 


\section{N Macrothink \\ International Journal of Learning \& Development \\ ISSN 2164-4063 2015, Vol. 5, No. 2}

Table 1.8 Computation of $\mathbf{f}$-ratio

Rating of the inferences of target markets of regulatory policies, activities and their presentations as indicies of perception.

\begin{tabular}{|c|c|c|c|c|c|}
\hline \multicolumn{2}{|c|}{ Consumers } & \multicolumn{2}{|c|}{ Regulatory Agencies } & \multicolumn{2}{|c|}{$\begin{array}{l}\text { Personnel of Firms in the Production } \\
\text { and Marketing of Consumer Products }\end{array}$} \\
\hline $\mathrm{X}_{\mathrm{A}}$ & $\mathrm{X}^{2} \mathrm{~A}$ & $\mathrm{X}_{\mathrm{B}}$ & $\mathrm{X}^{2} \mathrm{~B}$ & $\mathbf{X}_{\mathrm{C}}$ & $\mathrm{X}^{2} \mathrm{C}$ \\
\hline 14 & 195 & 16 & 256 & 28 & 784 \\
\hline 12 & 144 & 15 & 226 & 31 & 961 \\
\hline 10 & 100 & 13 & 169 & 32 & 1024 \\
\hline 09 & 81 & 14 & 196 & 30 & 900 \\
\hline 11 & 121 & 12 & 144 & 31 & 961 \\
\hline \multicolumn{2}{|c|}{$\sum \mathrm{X}_{\mathrm{A}}=56 \sum \mathrm{X}_{\mathrm{A}}=642$} & \multicolumn{2}{|c|}{$\sum \mathrm{X}_{\mathrm{B}} 70 \sum \mathrm{X}^{2} \mathrm{~B}=990$} & $\sum \mathrm{X}_{\mathrm{C}}=152$ & $\sum \mathrm{X}^{2} \mathrm{C}=4630$ \\
\hline \multicolumn{2}{|c|}{$\overline{\mathrm{x}}_{\mathrm{A}}=11.2$} & \multicolumn{2}{|c|}{$\overline{\mathrm{x}}_{\mathrm{B}}=14$} & \multicolumn{2}{|c|}{$\overline{\mathrm{X}}_{\mathrm{C}}=30.4$} \\
\hline \multicolumn{2}{|c|}{$\mathrm{n}=5$} & \multicolumn{2}{|c|}{$\mathrm{n}=5$} & $\mathrm{n}=$ & \\
\hline
\end{tabular}

$\operatorname{SSB}\left(\mathrm{S}_{\mathrm{B}}^{2}\right)=1900.09 ; \mathrm{SSW}\left(\mathrm{S}^{2}{ }_{\mathrm{W}}\right)=33.7$ and $\mathrm{SST}=\mathrm{SSB}+\mathrm{SSW}=1.933 .79$

Substituting for the mathematical notation:

$\mathrm{V}_{\mathrm{B}}=\frac{\mathrm{SSB}}{\mathrm{dfb}}$ and $\mathrm{V}_{\mathrm{W}}=\frac{\mathrm{SSW}}{\mathrm{dfw}}$

Where $V_{B}=$ Variance between group

$\mathrm{V}_{\mathrm{w}}=$ variance within group

$\mathrm{df}_{\mathrm{B}}=$ degree of freedom between group

$\mathrm{df}_{\mathrm{W}}=$ degree of freedom within group

$\mathrm{V}_{\mathrm{B}}=\underline{1.900 .09}=950.05$ 


$$
\mathrm{V}_{\mathrm{W}}=\underline{33.7}=2.81
$$

12

Substituting for F-ratio mathematical notation

$$
\begin{aligned}
& \mathrm{F}=\quad \underline{\mathrm{V}}_{\mathrm{B}}=\underline{950.05} \\
& \begin{array}{ll}
\mathrm{V}_{\mathrm{W}} & 2.81
\end{array} \\
& =\quad 338.09
\end{aligned}
$$

The ANOVA is summarized in table 1.9

Table 1.9 Summary of ANOVA

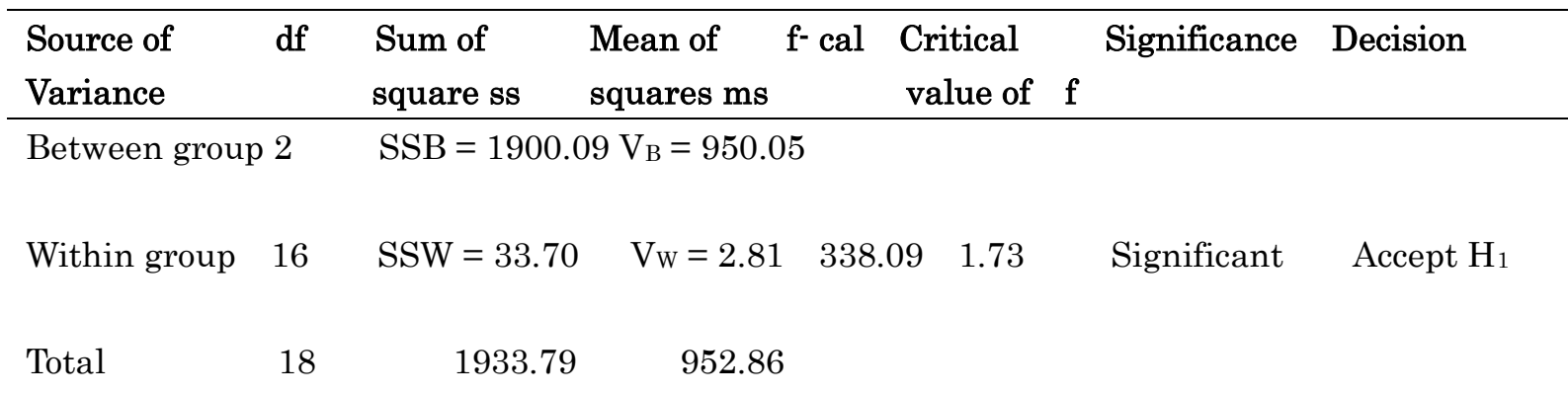

At 0.05 level of significance, the critical value of $f$ is given as 1.73 , $f$ cal $>\mathrm{f} 005$ (1.73), thus $\mathrm{H}_{1}$ is accepted. The conclusion is that significant difference exists between the inferences of consumers, government functionaries (regulatory agencies) and personnel of firms in the production and marketing of consumer goods in Nigeria have of the regulatory policies, activities and their presentations as indicies of consumer total perception of the policies. Hence the hypothesis, the inferences of target markets have concerning regulatory policies, activities and their presentations do not significantly influence consumer total perception of the regulatory policies and activities is not accepted.

\section{Findings:}

Findings of this study include:

- Key players in the consumer products industry as producers and marketers of goods and associated products as well as authorities in the industry's regulatory bodies are of 
the opinion that there is a significant linear relationship between the characteristics of the stimuli on which regulatory policies and activities are presented and the ability of the target markets to perceive the stimuli.

- Consumers of the products of the consumer products industry are of the opinion that there is no significant linear relationship between the characteristics of the stimuli on which regulatory policies and activities are presented and the ability of the target markets to perceive the stimuli.

- There is a significant difference between the assessments of personnel of the consumer products firms and those of products consumers on the regulatory agencies' presentations of stimuli as basis for enhancing the organization and integration of messages for the desired perception, given the impact of in-efficiency in the management of the activities of the personnel of the regulatory agencies.

- There is a significant difference between the inferences of consumers of the products of the Nigeria consumer products industry, government functionaries as regulatory agencies and personnel of the consumer products industry, of the regulatory policies, activities and their presentation as indicies of consumer total perception of the regulatory policies and activities.

\subsection{Discussion of Findings:}

Detailed study of the situation in the consumer products industry in Nigeria based on the perception of consumers of the industry's regulatory agencies, policies, activities and their presentations are as follows:

- There is a seemly great margin of variance in the assessments of the impact of consumer perception of the activities of the regulatory agencies compared with those of the regulatory agencies and personnel of firms in the industry. This is as a result of the poor and wrong perception consumers have about government regulatory policies and activities of the industry. This is attributed to in sufficiency of facts on regulatory policies and activities as made available to the publics. This is traced to the imbalance in the agencies' public education and promotion activities, techniques of message presentation and stimuli, as well as media and language of message presentations. Following this, consumers of the industry's products and other members of the publics have improper assessment of the efficiency rate of policies implementation on ceasure of poor standard products and products' registration and certification activities.

- Consumers of the products of the consumer products' industry in Nigeria assess members of the government functionaries as regulatory agencies as a set of corrupt persons, who exhibit high level of ostentious life style and lack discipline in the conduct of official duties. Equally observed, is the poor level of socialization of personnel of these agencies with members of the publics. Also observed is that, the agencies exhibit paucity of ability to execute judiciary exercises as they relate to consification of poor quality products and prosecution of persons (-natural or artificial) 
that indulge in the production and marketing of poor quality food and drugs. Thus stimuli of regulation as policies and activities are poorly perceived by products' consumers.

- These regulatory agencies mis-manage and exaggerate their promotional activities, ascribing success to themselves even when their failure rate is obviously high.

- Financial, physical, functional, social and psychological risks-Leon \& Leslie (1978) as associated with the consumption of the products of the Nigeria consumer products' industry is high among consumers. Financial risk is associated with fear that the products may not worth the cost; physical risk is traced to the danger of bodily harm associated with using the products; the functional risk is attributed to the low and poor level of performance of the products compared to consumer expectations, while the social risk involves anticipated or actual embarrassment associated with interaction directly or indirectly with other users or users of similar products but of high quality, resulting from consumers choice of products of the Nigeria consumer products' industry and the psychological risk as represented by the risk that the consumer products or brand there-to will hurt the ego (personality) of the users/buyer-Agbonifoh, Ogwo, Nnolim \& Nkamnebe (2007). These risks and their tendencies are not sufficiently addressed based on the promotions of the regulatory agencies neither by firms in the industry. Though these risks are high among consumers of products of Nigeria consumer products industry, they do not hinder patronage of the industry. Hence the industry has continued to grow and expand rather than develop.

This growth rather than development is attributed to the situation of lack of competition in the industry as well as low level of per capita income among consumers; hence tendency to patronizing foreign and higher quality product is low.

- The perception of the Nigeria consumers of the regulatory agencies and their activities is influenced by factors in the perceivers such as individual's moods, needs motives (motivations), memories, values, experiences, confidence, attentiveness, familiarity with the industry's regulatory policies and activities, the Nigeria culture of corruption as social and cultural as well as expectations of these customers of the regulatory agencies -Agbonifoh, Ogwo, Nnolim \& Nkamnebe (2007). Hence consumers develop perceptual vigilance, perceptual defence, selective attention, perceptual bias, halo effect and stereotype of the industry and the regulatory bodies. Citizens as consumers whose income level is above average make alternative choice of consumer products based on available and existing information as they are influenced by formed beliefs, attitude and intention, while poor consumers who are often in the majority, purchase whatever is available - majorly the poor products of the industry made available by unlicensed members of the industry as quarks who the regulatory policies and activities do not impact on. 


\section{Macrothink Institute ${ }^{\text {TM }}$}

- Interpretation as the act of assigning meaning to sensations, as created by the messages sent out by the consumer product regulatory agencies is poor among the target audience of the regulatory agencies. The message contents, contexts, structures, situations and media choice influence this interpretation. Thus members of the same target market in Nigeria assign different meanings to the messages of consumer product regulatory agencies, thus creating cognitive and or affective interpretation for variance in individual response to messages.

- Messages and the message development processes and activities of the consumer product regulatory agencies in Nigeria have not given quality attention to personal variables that affect message interpretation of learning and expectations of the different audience, neither has adequate considerations been given to the study of the situational characteristics of the populace as temporary, in terms associated with other states of mind -mood; available time to read and study messages; the physical characteristics of the Nigeria environment, the number and characteristics of other individuals within the environment, the nature of material composition of or that form basis of the message, external distractions as well as the reasons for the presentation of the message causes Nigerians to mis-interpret the message of the consumer product regulatory agencies-Hawkins, Best \& Coney (2001).

- There are problems associated with the characteristics of the stimuli, as the structure and nature of most messages as packaged and presented as advertisement do not create the desired impact on the markets' mental processing, thus expected meanings are not assigned to the messages. The role of semiotics as the science of how meaning is created, maintained and altered is not given desired recognition in the creation of consumer product regulatory messages.

- Similarly, targets of the Nigeria consumer products regulatory messages have problems of sensory discrimination, thus the ability of the individuals to distinguish between similar stimuli from different regulatory agencies is low. These regulatory agencies are expected to show marked difference between their message and those of other agencies in order for the target markets to notice same for expected impact. The adoption of the concept of just noticeable difference is low among the regulatory agencies in their messages presentation, thus the minimum amount that one regulatory agency's message differ from another with the difference still being notice is low. The regulatory agencies thus must strive to present messages on bill boards, radio, television, newspapers and other media for promotable difference between theirs and those of other agencies as inter and or intra industrial competitors, that must surpass the just noticeable difference.

- The regulatory agencies in the consumer product industry do not spend time to assess and ascertain the interpretation and response rate of the target market to their images (pictures) and words as bases of recommendations especially as pictures have different communication capacities. The role of rhetoric in the designing of regulatory 
agencies' promotional messages using pictures and other non verbal images has not been maximized, thus target markets as audience use their vocabulary of messages to read the messages, infer the regulatory agencies' intention, evaluate their argument and formulate responses-Philips (1997) and Friestad \& Wright (1999). Thus the importance of picture is emphasized thus- "A picture is worth a thousand words, not just because it may convey reality more efficiently than words but because it may convey meaning that words cannot adequately express"-Hawkins, Best \& Coney (2001).

- Message presentations of regulatories agencies in the consumer product industry in Nigeria create room for consumers to make inferences. Hence available data, based on the target markets own ideas aid the consumers infer for completeness of the message. As desired information is not often complete in these messages, consumers assign value to the messages based on the presumed or actual relationship that exist between the personnel of these regulatory agencies given their level of socialization, affluent and ostentious lifestyle and corrupt tendencies as attributes and those on which data are available. This leads to the mis-interpretation of the messages of these consumer product regulatory agencies, as product of incorrect inferences by the target audience. The regulatory agencies in the Nigeria consumer products industry as marketers, public officers and agents of social change in their desire to communicate with the general or specific publics do not pre-test their messages carefully to ensure correctness in their interpretation.

\section{Conclusion:}

Through the products of the Nigeria consumer products industry may not be adjudged poor in quality, neither the activities of the regulatory agencies far below expectations, however, the activities of the industry's regulatory agencies place the industry in bad light given the expectations of consumers, thus consumer perception is distorted for bias against the industry and its products, policies and activities. It is therefore important that the industry based on the activities of its key players should be repositioned.

\section{Recommendations:}

This work recommends as follows:

- The Nigeria consumer products regulatory agencies and its market offer as products need to be repositioned in terms of how consumers perceive them. This is in terms of how consumers perceive the regulatory agencies, policies and their associated activities.

- Reposition objective of the consumer products regulatory agencies in Nigeria and the activities of its regulatory agencies is achievable based on either or a combination of changes in the attributes of the message, media, language of presentation and policy inputs in line with expected (desired) direction as goal and for efficiency in the integration of regulatory agencies promotion intra mix elements to create desired impact on the perception of the actual and potential customers. Given this, 
socialization of personnel of the regulatory agencies with target publics is recommended as well as the creation of balance in the urban/rural target market education on the activities of the regulatory agencies.

- Increase in the total exposure rate of regulation policies messages to the target audience with activities aimed at eliminating negative tendencies associated with low level of discipline of personnel of the regulatory agencies which have negative impact on consumer perceptions is recommended.

- Regulatory messages in major languages of the Nigerian society should be encouraged and bill boards should be placed at high traffic areas to capitalize on increase exposure.

- Messages should be designed with highly visible marks and overhead signs to make message location easier.

- The role of alphanumeric names (worded letter combination) should be maximized for effectiveness in influencing the perception of target markets positively.

- Graphics as part of the regulatory agencies' messages is advocated for, as personal attributes of natural and artificial persons adjudge trustworthy, of high ethical standard and whose lifestyle confirm with expectations should be highlighted.

- Based on the fact that target audience exposure process is selected rather than random, care should be taken to determine the media, the target audience are most frequently exposed to, for the placement of regulatory policy messages given the divide between the urban and rural people as well as literate and illiterate and variation in social status.

- Media target must also consider the ethnic group, social class, family life style as well as other demographic variables of the general and specific target audience.

- Promotion messages of the regulatory bodies should aim at always capturing attention and creating meaning. This must consider reasonably the defined target market characteristics, the nature, content, structure and context of the message as well as the message situation. It must also consider the fact that the Nigeria audience may not attach value to the message of the regulatory agencies unless and until they are involved in one problem or the other, hence stimuli characteristics such as bright, animated cartoons or surrealism may be adopted to catch target market attention. Alternatively, messages should be tied to topics that will catch the interest of the audience. Efforts must also be made to avoid the danger of negative impact on attention to or interpretation of the cardinal message.

- Regulatory messages should be developed with special regards to ethical and legal considerations of placement of warning labels on products. These warnings could be general and or specific, alerting the target market on the risks associated in adopting specific products. Warning as part of the promotional message of the regulatory agencies should aim at alerting actual and potential users of consumer products on the 


\section{$\Lambda$ Macrothink}

risks associated with the adoption of products rather than compelling same to stop the adoption. Such warning should achieve the objective of allowing the target market to make informed decisions concerning the product as offered.

- Warning as promotional message influence beliefs, knowledge and causes change in behaviour. It is therefore important for the regulatory agencies in Nigeria to adjust to the challenges associated with the designing of consumer product warnings messages that will maximize chances of goal actualization. This should involve the creation of consonance between personality of the target audience as exhibited in their needs and the level of understanding of related vocabularies of the designed warning messages. This consonance may be achieved based on well executed consumer research exercise that identifies the characteristics of the markets for which the warning is targeted to and for the options that have increased probability of affecting the target audience positively.

\section{References:}

Adewakum, A \& Bello S. (2013), "Apathy, Weak Legislation, Major Disincentive to Consumerism in Nigeria-Stakeholders". www.tribune.com.ng/--/7854-aparthy-weak-legislation-major-disincentive

Adekanmbi, D. (2012), Mobile Authentication Services in Nigeria Tribune, Monday November 5, 2012.

Adinoyi, Ojo; Ogunseitan, Okwara, J, Ogbeide, E \& Anukuru, O. (1988), "Worrying Cracks in Medical Practice" The Guardian, Sunday September 18.

Agbonifoh B. A; Ogwo E.O, Nnolim D.A \& Nkamnebe A.D (2007), Marketing in Nigeria Concepts, Principles and Decision. Aba- Nigeria Afrotowers Books.

Agbonifoh, B A (1987), "Operationalising the Societal Marketing Concept: A Rationale and A Guide" Anan Journal of Society, Culture and Environment Vol. II, No 1, December

Akin, A \& Shue, B (2013), Apathy, Weak Legislation, Major Distinction to Consumerism in Nigeria Stakeholder, www.tribune.com..ng/../7854.aparty-weak-legislation.major.distintion.

Akerele, B. (1980), The Relevance of Consumerism for a Developing Economy, Nigeria. Journal of Marketing. 2 (December).

Anyanwu, A (2005), Consumer Behaviour, Powerpoint Approach; Owerri. Alvan Global Publications

Ayozie, D.O (2013), "Consumerism the Shame of Marketing in Nigeria: Challenges to Corporate Practices" Universal Journal of Management and Social Sciences.

Assel, H. (1992), Consumer Behaviour and Marketing Action 4th Edition, USA PWS-KENT: Publishing Company 
Aimiuwa, L (2013), “Apathy, Weak Legislation, Major Disincentive to Consumerism in Nigeria-Stakeholders' in Adewakun, A. \& Bello, S. www.tribune.com.ng/.../7854apathy-weak-legislation-major-discentive Retreived 22 March, 2013.

Ekenma, C.C (1987), "The Influence of Marketing on Consumers in a Production Oriented Economy: A Case Study of Consumers in Okigwe and Owerri B. Sc Project Report. Imo State University Okigwe August.

Friestad, M. \& Wright, P. (1999) "Everyday Persuasion Knowledge" Psychology and Marketing-March.

Halliru, M (2012), The Development of Consumerism in Nigeria: Prospects and Challenges. International Journal of Arts and Commerce Vol. No.4

Hawkins, D. I., Best, R. J \& Coney, K. A (2001), Consumer Behaviour Building Marketing Strategy, Boston, Irwin McGraw-Hill

Ijewere, A A \& Obeke, S. O (2011), Consumerism in Nigeria JORIND 9(2) December. ISSN 1596-8308www.iramscapus.org., www.ajol.info/journals/jorind.

Leon G. Schiffoman \& Lestie L Kanuk (1978), Consumer Behaviour New Jersey: Prentice Hall India

Nwokoye N. G. (1989), Modern Marketing in Nigeria. London Macmillan Press Ltd. Pp 41-45

Odutayo S. O (1989), Concept of Consumerism in Nigeria: Marketing Journal A Quarterly Publication of the Nigeria Marketing Association Vol. 2 No 5, January-March

Ogbide, M. (1981), Smuggling: Nigeria's Growth Industry, National Concord February

Oghuma A, Arinze, D \& Mba, J. (1988), “NITEL's IDD Battle: Victoria Island Resident Kick as NITEL Forces IDD on Them. Newswatch September 26,

Ogwo, E. O (1999), Introduction to Marketing. Lecturer Material, Abia State University, Uturu, Unpublished.

Ogwo, E. O., (2012), Marketing Research. Abia State University, Uturu, Lecturer Material, Unpublished.

Oko, A. E. Ndu \& Ogwo E. Ogwo (2014), "Self Regulation in the Marketing of Services in Nigeria: Study Selected Firms in the Service Industry Global Journal of Emerging Trends in e-Business, Marketing and Consumer Psychology

Oko, A. E. Ndu \& Agbonifoh, B. A (2014), "Corporate Social Responsibility in Nigeria: A Study of the Petroleum Industry and The Niger Delta Area". International Review of Social Sciences and Humanities (IRSSH). Volume 6, No. 2 January.

Oko, A. E. Ndu \& Osuagwu, L (2013), "Consumerism the Nigeria Experience: Study of the Food and Drink Industries 1980-2012". Business and Management Horizons ISSN 
2326-02797. Vol.1 No 2.

Oloke, A. (1988), "Where Ignorance is Bliss" Newswatch Sept. 26,

Olusoga, S. A (1978), The Marketing Concept in a Developing Economy-A Critical Appraisal. Nigeria Journal of Business Management, July/August

Omenazu, P. (2010), Consumer Protection in Nigeria. Retrieved August 4, 2011, from $\mathrm{http} / /$ trifter.com/Africa/Nigeria/consumer-protection in-nigeria

Philip, B. J (1997), “Thinking into It” Journal of Advertising -Summer.

---Social, Political, Economic and Environmental Issues that Affect Us All-www.globalissues.org. Retrieved on the 20th June 2013. 